\title{
O USO DE PLANTAS ABORTIVAS NO NORDESTE BRASILEIRO: UMA REVISÃO
}

\section{THE USE OF ABORTIVE PLANTS IN NORTHEAST BRAZIL: A REVIEW}

\author{
Andreia Magnólia Marques NUNES ${ }^{1}$; Valdeline Atanazio da SILVA ${ }^{1 *}$ \\ ${ }^{1}$ Universidade Federal Rural de Pernambuco (UFRPE), Campus Serra Talhada (UAST), Serra Talhada, Pernambuco, \\ Brasil. \\ *valdeline@yahoo.com.br
}

Submitted: 08/11/2020; Accepted: 25/01/2021; Published: 19/03/2021

\section{RESUMO}

O uso de plantas para fins abortivos é frequente no Brasil, embora seja prática proibida por lei. O presente trabalho é uma revisão bibliográfica sobre as espécies registradas como abortivas no nordeste brasileiro. Para o desenvolvimento da pesquisa realizou-se um levantamento de artigos sobre o tema e utilizou-se como palavras-chave os seguintes termos: "plantas abortivas", abortivas, aborto. Foram pesquisados trabalhos sobre etnobotânica, produções que tratavam sobre aborto, bem como o uso de plantas para este fim. Após a seleção dos artigos, dados de 35 trabalhos foram usados nesta revisão. $\mathrm{O}$ conhecimento sobre o uso dessas espécies é oriundo de benzedeiros, feirantes, donas de casa, estudantes e gestantes, com idade variando entre 13 e 96 anos. As motivações citadas para a prática do aborto foram: presença de outros filhos, ausência de companheiros, financeiro e questões religiosas, embora as religiões comentadas, evangélica e católica, condenem a prática. De um total de 79 plantas, as mais apontadas foram: Luffa operculata e Coutarea hexandra (citada oito vezes), Aspidosperma pyrifolium (citada seis vezes), Manihot cf. dichotoma e Peumus boldus (citada cinco vezes) e, Anadenanthera colubrina (citada quatro vezes). De modo geral, as mulheres utilizam as plantas sem o entendimento que, embora sejam naturais, apresentam propriedades que podem levar à morte, tanto que algumas usam tais espécies sem o objetivo de abortar, mas para diminuir ansiedade e combater desconfortos digestivos, desconsiderando suas contraindicações de uso. Algumas delas citaram, ainda, a utilização de artifícios na prática de "aborto" sem que estivessem de fato grávidas. Sendo assim, é importante que campanhas sejam realizadas para maior compreensão sobre o uso de plantas medicinais e seus efeitos colaterais, seja para grávidas, seja para a população em geral.

PALAVRAS-CHAVE: Aborto, Etnobotânica, Plantas medicinais, Plantas tóxicas, Saúde da mulher.

\begin{abstract}
The use of plants for abortive purposes is a frequent in Brazil, although it is a practice forbidden by law. The present work is a literature review regarding species registered as abortive, in the Northeast region of Brazil. For the development of this research it was performed a survey research regarding the subject and it was used as keywords the following expressions: "abortive plants", abortive, abortion. There were searched studies about ethnobotany, researches about abortion, as well as the use of plants for this purpose. After the selection of the articles, data from 35 researches were used in this review. The knowledge regarding the use of these species is native from healers,
\end{abstract}


fair dealers, housewives, students and pregnant women, with ages between 13 and 96 years old. The motivations cited for the practice of abortion were: presence of other children, absence of companions, financial and religious issues, even though the mentioned religions, evangelical and catholic, condemn the practice. From a total of 79 plants, the most cited were: Luffa operculata e Coutarea hexandra (cited eight times), Aspidosperma pyrifolium (cited six times), Manihot cf. dichotoma e Peumus boldus (cited five times) and Anadenanthera colubrina (cited four times). In general, women use plants without the understanding that although they are natural, they present properties in which may lead to death, and some of them use such species without the purpose of aborting, but to decrease anxiety and to oppose digestive discomforts, disregarding their contraindications of use. Some of them even cited the use of techniques in the practice of "abortion", without being effectively pregnant. Therefore, it is important that campaigns are developed for a better comprehension about the use of medicinal plants and their side effects, either for pregnant women or for the general population.

KEYWORDS: Abortion, Ethnobotany, Medicinal plants, Toxic plants, Women's health.

\section{INTRODUÇÃO}

No Brasil, o aborto é uma prática cujos dados são inconsistentes, cerca de 200 mil internações efetuadas apresentam-no como motivo e, menos de 1\% tem origem médica ou legal (CECATTI et al., 2020). Desses registros de internações originam-se os dados sobre a prática no Brasil, contudo, não se tem um registro preciso sobre o número de abortos ocorridos no país (CARDOSO et al., 2020). Os autores consideram que há necessidade de maior cuidado e planejamento na atenção às grávidas para evitar o abortamento, seja ele espontâneo ou provocado.

O uso de recursos vegetais para os mais diferentes fins no Nordeste é observado em diversos artigos, tais como: Alves et al. (2007) e Anselmo et al. (2012) que apontam a utilização das espécies em feiras livres e mercados; Carvalho et al. (2012), Brito et al. (2009), Chaves e Barros (2012) em comunidades; Bakke et al. (2008) em universidades; Barros e Albuquerque (2005), Pires e Araújo, (2011) em UBS (Unidades Básicas de Saúde). Na região, as mulheres fazem uso dessas plantas com objetivo abortivo e/ou medicinal para diminuir desconfortos digestivos, estresse e ansiedade durante a gestação, contudo, muitas vezes, sem compreender que essas plantas podem causar efeitos nocivos a elas ou ao feto (BARROS e ALBUQUERQUE, 2005). Muitas usuárias afirmam que pelo recurso ser natural não há problemas em utilizá-lo (PIRES e ARAÚJO, 2011; MELO et al., 2016).

Pouco ainda se conhece sobre a relação das mulheres com a prática do aborto, principalmente no nordeste brasileiro, como exemplifica um artigo de Diniz et al. (2009), onde afirma-se que $75 \%$ de estudos sobre o tema foram realizados no Sudeste e apenas $14 \%$ 
NUNES, A. M. M.; SILVA, V. A. O uso de plantas abortivas no Nordeste Brasileiro: uma revisão. Ethnoscientia v.6 n. 2 , especial, 2021. DOI: $10.22276 /$ ethnoscientia.v6i2.370

deles no Nordeste. Sendo assim, justifica-se a realização deste trabalho em pesquisar, através da literatura, o uso de plantas abortivas no nordeste brasileiro que, embora ainda discreto no volume de dados, chama atenção para a necessidade de melhor entendimento sobre uso das espécies durante a gravidez, pois tais recursos "medicinais", se usados de forma indevida, podem ser perigosos tanto para a gestante, quanto para o filho.

\section{MATERIAIS E MÉTODOS}

O presente estudo pauta-se numa abordagem qualitativa por meio de pesquisa bibliográfica, a partir de fontes secundárias sobre plantas com efeitos abortivos/tóxicos em grávidas no nordeste brasileiro. Realizou-se, entre junho de 2019 e abril de 2020, um levantamento de dados nas plataformas Google e Google Acadêmico baseado em artigos escritos em português e inglês, publicados entre os anos 2000 até 2019. As palavras-chave utilizadas durante as buscas foram: abort and plants, abortivo, abortiva, "plantas medicinais", "gestantes and abortiva", teratogênico.

Foram analisados, como fonte de dados, 35 artigos e seus dados organizados em planilha Excel. Este total resulta de uma triagem que levou em consideração trabalhos relacionados ao Nordeste e o conhecimento/uso das plantas como recurso abortivo. Foram excluídos do total de escritos levantados: artigos de revisão (para evitar duplicidade de resultados), artigos com identificação equivocada de espécies, trabalhos com dados confusos ou pouco claros. Na discussão dos dados dos artigos usados na Planilha Excel, utilizou-se informações oriundas de revisões, monografias, dissertações e teses.

Todos os dados levantados nos artigos foram plotados em planilhas do Excel e, posteriormente, efetuadas suas análises.

\section{RESULTADOS E DISCUSSÃO}

O aborto é um procedimento adotado por mulheres, mas complexo em vários aspectos, tornando-o objeto de difícil estudo (MENEZES et al., 2020). Muitos casos de aborto provocado são descritos como "espontâneos" ao serem atendidos no sistema de saúde (MENEZES et al., 2020). A Organização Mundial de Saúde (OMS, 2013) considera que vários fatores, principalmente a ausência de recursos financeiros, levam as grávidas ao uso de recursos vegetais em seus cuidados de saúde. De acordo com Barros e Albuquerque (2005), o aborto é um assunto considerado tabu entre as mulheres e, frequentemente, evitado entre as mesmas. Para Silva et al. (2010), muitas são as praticantes do aborto por motivos socioeconômicos ou por não estarem em um relacionamento conjugal. Inúmeros 
NUNES, A. M. M.; SILVA, V. A. O uso de plantas abortivas no Nordeste Brasileiro: uma revisão. Ethnoscientia v.6 n. 2 , especial, 2021. DOI: $10.22276 /$ ethnoscientia.v6i2.370

são os elementos usados para o aborto, as plantas, por exemplo, são um deles (SILVA et al., 2010).

Um total de 79 espécies vegetais são mencionadas na presente revisão como abortivas. As mais citadas, desse total, foram: Luffa operculata (L.) Cogn e Coutarea hexandra (Jacq) K. Schum (apontadas oito vezes), Aspidosperma pyrifolium Mart. \& Zucc (apontada seis vezes), Manihot cf. dichotoma Ule e Peumus boldus Molina (apontadas cinco vezes), Anadenanthera colubrina (Vell.) Brenan (apontada quatro vezes). Essas espécies destacaram-se em outros estudos, como nos de Arcanjo et al. (2013) e Gorril et al. (2016), que salientaram o uso de Peumus boldus em sua revisão sobre plantas abortivas no Brasil.

O conhecimento e a aquisição dessas plantas foi registrado em diferentes ambientes e pertence a diversas pessoas, tais como: feiras livres e mercados (ALVES et al., 2007; ALVES e NASCIMENTO, 2010 e ANSELMO et al., 2012); em comunidades/donos de casa (BRITO et al., 2009; CARVALHO et al., 2012; CHAVES E BARROS, 2012; PEDROSA et al., 2012; FEIJÓ et al., 2013; NETO et al., 2014; OLIVEIRA et al., (2014); CASTRO et al, 2016); em universidades (BAKKE et al., 2008); com indígenas (ALBUQUERQUE et al., 2011); VASCONCELOS e CUNHA, 2013); grávidas em UBS (Unidade Básica de Saúde) Barros e Albuquerque, (2005), Pires e Araújo, (2011); quilombolas (GOMES e BANDEIRA, 2012; SILVA et al., 2012).

Luffa operculata (L.) Cogn é encontrada principalmente nas regiões Norte e Nordeste do Brasil. No presente trabalho, é uma das principais espécies citadas como abortiva (ROQUE et al., 2010; SILVA e FREIRE, 2010; SILVA et al., 2010); MADALENO, 2011) por feirantes, raizeiros (GOMES et al., 2008; MADALENO, 2011; ANSELMO et al., 2012), benzedeiras, agricultores, grávidas e universitárias (BAKKE et al., 2008). É uma espécie usada, sobretudo, no tratamento de sinusite e no preparo de garrafadas com finalidade abortiva no norte e nordeste brasileiros (MATOS, 1979), corroborando com o observado por Mengue et al. (2001) e Gorril et al. (2016) em seus trabalhos, onde reiteram o uso da espécie no tratamento de sinusites (MENGUE et al., 2001; ANSELMO et al., 2012) e rinites, contudo, seu uso pode acarretar hemorragia e irritação nasal devido sua toxicidade, mas este efeito ocorre apenas em alguns casos (MENGUE et al., 2001).

Coutarea hexandra (Jacq) K. Schum juntamente com Luffa operculata é uma das principais plantas citadas como abortiva nos estudos analisados. Neste estudo, observou-se sua menção por quilombolas, feirantes (LIMA et al., 2016), benzedeiros, conhecedores de 
NUNES, A. M. M.; SILVA, V. A. O uso de plantas abortivas no Nordeste Brasileiro: uma revisão. Ethnoscientia v.6 n. 2 , especial, 2021. DOI: 10.22276/ethnoscientia.v6i2.370

medicinais (MACEDO et al., 2018), como espécie usada para abortos. O efeito mutagênico da espécie foi registrado por Nunes et al. (2012) e, juntamente com os ensaios etnofarmacológicos realizados por Lucena et al. (2006), confirmaram seus efeitos antiinflamatórios e anticonceptivos. Feirantes citaram essa variedade para o tratamento, também, de amenorreia, sinusite e fortalecimento do sangue (ALVES et al., 2007).

Aspidosperma pyrifolium Mart. \& Zucc., citada como abortiva (ROQUE et al., 2010; GUERRA et al., 2012; ROQUE e LOIOLA, 2013), é forrageira (GUERRA et al., 2012; LUCENA et al., 2012) e utilizada como combustível e na construção de casas (GUERRA et al., 2012; LUCENA et al., 2012). Na produção alimentícia e tecnológica também, é destaque (SOARES et al., 2013), bem como para o tratamento de gripe e dor de dente (SILVA e FREIRE, 2010). Tais informações ratificam a diversidade de uso da espécie.

Manihot cf. dichotoma Ule, referida como abortiva (CARVALHO et al., 2012; GUERRA et al., 2012; LEITE et al., 2012; SOARES et al., 2013) e considerada uma espécie forrageira (CARVALHO et al., 2012; SOARES et al., 2013), tem seu uso destinado, também, à tecnologia (CARVALHO et al., 2012; LUCENA et al., 2012; SOARES et al., 2013), bem como à produção alimentícia e de combustíveis (SOARES et al., 2013).

Peumus boldus Molina é citada como abortiva por gestantes (PIRES e ARAÚJO, 2011), contudo, outras mulheres classificam a planta como medicinal e indicam que seu uso é valoroso para diminuir o desconforto digestivo (PONTES et al., 2012; ARAÚJO et al., 2016). Conforme Bakke et al. (2008), o uso da espécie é frequentemente realizado por universitárias na prática abortiva. Corroborando com essa ideia, Ruiz et al. (2008) afirmam que o chá dessa planta pode ocasionar teratogenia do feto no primeiro trimestre de gestação.

Outras enfermidades também tratadas com um produto vegetal derivado da Peumus boldus Molina são as relacionadas às questões hepáticas. Soares et al. (2015), em seus estudos, salientam que deve ser realizada uma fiscalização mais incisiva sobre tal produto, pois suas embalagens carecem de informações sobre seu modo e quantidade de uso.

Apesar de Anadenanthera colubrina (Vell.) Brenan não ser a mais citada nos estudos, é uma das reconhecidas como abortiva/tóxica pelas respondentes, gestantes ou não. (CARVALHO et al., 2012; GUERRA et al., 2012; LUCENA et al., 2012; SOARES et al., 2013). A planta apresenta uma diversidade de usos medicinais, sendo utilizada, por exemplo, no tratamento de tosse (ALBUQUERQUE, 2006; ALBUQUERQUE e OLIVEIRA, 2007; AGRA et al., 2007), de problemas respiratórios e estomacais (CORDEIRO e FELIX, 2014), como no trato da gripe e do catarro (SILVA et al., 2012). 
NUNES, A. M. M.; SILVA, V. A. O uso de plantas abortivas no Nordeste Brasileiro: uma revisão. Ethnoscientia v.6 n. 2 , especial, 2021. DOI: $10.22276 /$ ethnoscientia.v6i2.370

Além de também possuir ação anti-inflamatória (SILVA e FREIRE, 2010; SILVA et al., 2016), a espécie tem seus usos ligados recorrentemente à tecnologia, à produção alimentícia e de combustíveis (SOARES et al., 2013).

O uso desses recursos vegetais pode estar associado ao difícil acesso aos cuidados de saúde utilizando o SUS (Sistema Único de Saúde), e à informação sobre o uso dessas espécies (BAKKE et al., 2008). Esses autores, ao analisarem a utilização e o conhecimento sobre plantas abortivas por alunas de graduação das áreas de Saúde e Humanas, mostram que elas citam, basicamente, as mesmas espécies sabendo das consequências de seu uso estando grávidas. E 6,25\% das estudantes afirmaram que qualquer planta pode ser abortiva, dependendo da dose consumida (BAKKE et al., 2008).

$\mathrm{O}$ uso de plantas medicinais entre grávidas ocorre por vários motivos, para fins abortivos, como calmante, no trato de problemas digestivos (BAKKE et al., 2008), para aliviar constipação, dor, febre e ansiedade (PONTES et al., 2012). Dependendo de como as espécies são manipuladas, podem apresentar efeitos cicatrizantes e relaxantes (PIRES e ARAÚJO, 2011), mas também reações adversas como vômito, enjoo e dores musculares (GORRIL et al, 2016). Embora, neste estudo, a Cannabis sativa seja espécie pouco citada, é sabido que seu uso é recorrente, apesar de muitas pessoas não comentarem isso abertamente. Segundo Silva et al. (2019), essa é a planta mais utilizada por gestantes como calmante e pode levar a: aborto, problemas durante o parto, baixo desenvolvimento intelectual e físico do bebê.

Inúmeras mulheres utilizam Peumus boldus (60\% delas), Melissa officinalis e Cinnamomum zeylanicum sem conhecimento prévio dos efeitos de tais plantas sobre o feto (PONTES et al., 2012). Tal desconhecimento também foi observado por outros autores que afirmam, ainda, que por ser natural as usuárias acreditam que não causará nenhum dano aos seus organismos (MOREIRA et al., 2001; BARROS e ALBUQUERQUE, 2005; BAKKE et al., (2008); PIRES e ARAÚJO, 2011). Um total de 6,25\% de graduandas reconhece que toda planta apresenta algum efeito grave/danoso, dependendo da dose usada (BAKKE et al., 2008). Mengue et al. (2001) consideram que as plantas embora sejam naturais, não significa que sejam atóxicas, pelo contrário, algumas espécies são extremamente tóxicas, como citaram Ruiz et al. (2008) em relação ao uso de boldo (Peumus boldus), pois muitas pessoas, inclusive mulheres em período gestacional, utilizam tais espécies sem o devido conhecimento sobre suas propriedades e como usá-la corretamente. Mengue et al. (2001), consideram, ainda, que outros aspectos devem ser observados quanto ao uso de plantas medicinais, como coleta, secagem e armazenamento. 
NUNES, A. M. M.; SILVA, V. A. O uso de plantas abortivas no Nordeste Brasileiro: uma revisão. Ethnoscientia v.6 n. 2 , especial, 2021. DOI: $10.22276 /$ ethnoscientia.v6i2.370

Algumas mulheres relataram a ocorrência de abortos "espontâneos" como resultados de eventos não relacionados ao uso de plantas, mas diretamente ligados a sustos e brigas, contudo, apontaram a utilização de medicamentos indicados para outros fins, como o misoprostol e suco de uva que, embora não seja medicamento, assim foi classificado pelas usuárias. (BARROS e ALBUQUERQUE, 2005). É valido ressaltar que o uso de suco de uva como recurso abortivo não possui comprovação científica. Moreira et al. (2001) registraram que em 16\% de mulheres que citaram uso de substâncias abortivas, 10\% tiveram crianças com malformação congênita.

Meninas com idade entre 12 e 13 anos foram citadas nos estudos analisados como conhecedoras de plantas abortivas e/ou usuárias de tais espécies (BARROS e ALBUQUERQUE, 2005). Uma garota de 13 anos afirmou tentar abortar usando, sem sucesso, chá de Catharanthus roseus. Neste caso, o bebê nasceu sem qualquer tipo de sequela. Barros e Albuquerque (2005) pesquisaram grávidas entre 13 e 21 anos de idade, $25 \%$ delas confirmaram o uso de alguma substância para induzir o aborto. Silva et al. (2010) também registraram a presença de meninas de 12 anos entre as que utilizam/conhecem espécies abortivas, algo extremamente preocupante que demonstra a ausência de políticas públicas de saúde para o cuidado dessas meninas, em geral, de baixa renda.

\section{CONCLUSÃO}

Observou-se, por meio dos dados pesquisados, que dentre as espécies utilizadas como abortivas, destacaram-se: Luffa operculata, Coutarea hexandra, Aspidosperma pyrifolium, Manihot cf. dichotoma, Anadenanthera colubrina e Peumus boldus.

Notou-se que muitas mulheres utilizam plantas medicinais durante a gravidez para diminuir incômodos como enjoo, problemas digestivos e crises de ansiedade, mas desconhecem alguns efeitos colaterais das espécies, provocando algumas vezes, inclusive, malformação congênita do feto quando as utilizam, sem êxito, como recurso abortivo.

É urgente o estabelecimento de políticas públicas de saúde que auxiliem e informem meninas e mulheres que têm praticado o aborto, pois tal prática, quando realizada de forma amadora, é extremamente perigosa à vida, principalmente em mulheres muito jovens. É pertinente salientar que tal colocação não faz juízo de valor à prática, e sim propõe o esclarecimento dessas meninas/mulheres.

Considera-se que as políticas públicas de saúde aqui sugeridas devem ser estendidas às Unidades Básicas de Saúde (UBS) para informar às mulheres grávidas sobre o perigo no 
NUNES, A. M. M.; SILVA, V. A. O uso de plantas abortivas no Nordeste Brasileiro: uma revisão. Ethnoscientia v.6 n. 2 , especial, 2021. DOI: $10.22276 /$ ethnoscientia.v6i2.370

uso de plantas medicinais durante essa fase da vida, porque, mesmo seus usos sendo destinados a outros fins não relacionados à prática abortiva, quando utilizadas incorretamente podem ocasionar malformação do feto ou sua morte indesejada.

A partir da pesquisa aqui apresentada, percebeu-se que há, na literatura científica a necessidade de mais estudos que tratem sobre a relação sobre os usos corretos de plantas abortivas e/ou medicinais por mulheres.

\section{REFERÊNCIAS BIBLIOGRÁFICAS}

AGRA, M. F. et al. Medicinal and poisonous diversity of the flora of "Cariri Paraibano", Brazil. Journal of ethnopharmacology, v. 111, n. 2, p. 383-395, 2007. Disponível em: < https://doi.org/10.1016/j.jep.2006.12.007>. Acesso em: 17 fev. 2020.

ALBUQUERQUE, U. P.; OLIVEIRA, R.F. The use-impact on native Caatinga species in Brazil reduced by the high species richness of medicinal plants? Journal of ethnopharmacology, v. 113, n. 1, p. 156-170, 2007. Disponível em: $<$ https://doi.org/10.1016/j.jep.2007.05.025>. Acesso em: 05 abr. 2020.

ALBUQUERQUE, U.P. et al. Use and extraction of medicinal plants by the Fulni-ô indians in northeastern Brazil: implications for local conservation. Sitientibus série Ciências Biológicas, v. 11, n. 2. p. 309-320. 2011. Disponível em: $<$ http://periodicos.uefs.br/index.php/sitientibusBiologia/article/view/78>. Acesso em: 19 dez. 2019.

ALBUQUERQUE, U.P. Re-examining hypotheses concerning the use and knowledge of medicinal plants: a study in the Caatinga vegetation of NE Brazil. Journal of Ethnobiology and Ethnomedicine, v.2, n. 1, p. 1-10. 2006. Disponível em: $<$ https://www.ncbi.nlm.nih.gov/pmc/articles/PMC1557484/>. Acesso em: 27 jan. 2020.

ALVES, R. R. N. et al. Utilização e comércio de plantas medicinais em Campina Grande, PB, Brasil. Revista eletrônica de farmácia, Goiânia, v. 4, n. 2, p. 176-193, 2007. Disponível em: <https://doi.org/10.5216/ref.v4i2.3060>. Acesso em: 19 dez. 2019.

ALVES, R. R. N.; NASCIMENTO, S. S. Levantamento fitogeográfico das plantas medicinais nativas do cariri paraibano. Rev. Geogr. Acadêmica, v. 4, n. 2, p. 73-86, 2010. Disponível em: $<$ https://biblat.unam.mx/hevila/Revistageograficaacademica/2010/vol4/no2/7.pdf $>$.Acesso em: 04 fev. 2020.

ANSELMO, A. F. et al. Levantamento etnobotânico de plantas medicinais comercializadas por raizeiros em uma feira livre no município de Patos-PB. Revista de Biologia e Farmácia, Campina Grande, v. especial, p. 39-48, 2012.

ARAÚJO, C. R. F. et al. Use of Medicinal Plants with Teratogenic and Abortive Effects by Pregnant Women in a City in Northeastern Brazil. Revista Brasileira de Ginecologia e Obstetrícia, Rio de Janeiro, v. 38, n. 3, p. 127-131, 2016. Disponível em: $<$ https://doi.org/10.1055/s-0036-1580714>. Acesso em: 04 abr. 2020. 
NUNES, A. M. M.; SILVA, V. A. O uso de plantas abortivas no Nordeste Brasileiro: uma revisão. Ethnoscientia v.6 n. 2 , especial, 2021. DOI: 10.22276/ethnoscientia.v6i2.370

ARCANJO, G. M. G. et al. Estudo da utilização de plantas medicinais com finalidade abortiva. Revista Eletrônica de Biologia (REB). ISSN 1983-7682, v. 6, n. 3, p. 234-250, 2013. Disponível em: <https://revistas.pucsp.br/reb/article/view/13347>. Acesso em: 14 fev. 2020.

BAKKE, L. A. et al. Estudo comparativo sobre o conhecimento do uso de plantas abortivas entre alunas da área. Revista Eletrônica de Farmácia, Goiânia, v. 5, n. 1, p. 24-31, 2008. Disponível em: <https://doi.org/10.5216/ref.v5i1.4611>. Acesso em: 19 dez. 2019.

BARROS, F. R. N.; ALBUQUERQUE, I. L. Substâncias e medicamentos abortivos utilizados por adolescentes em unidade secundária de saúde. Revista Brasileira em Promoção da Saúde, Fortaleza, v. 18, n. 4, p. 177-184, 2005. Disponível em: $<$ https://periodicos.unifor.br/RBPS/article/view/941>. Acesso em: 22 mar. 2020.

BARROS, S.S. et al. Prática de interrupção da gravidez utilizando plantas medicinais embriotóxicas e abortivas e a atuação de profissionais da saúde como instrumento na conscientização contra esta prática. In: Org. Samuel Miranda Mattos, Kellen Alves Freire. Atenção interdisciplinar em saúde 2. Ponta Grossa, PR: Atena Editora, 2019. Cap. 18, 191 a 199.

BRITO, V. F. S. et al. Plantas medicinais utilizadas pela comissão de mulheres na zona rural no município de Lagoa Seca-PB. Revista de Biologia e Farmácia, Campina Grande, v. 3, n. 1, p. 112-123, 2009.

CARDOSO, B. B. et al. Aborto no Brasil: o que dizem os dados oficiais?. Cadernos de Saúde Pública, Rio de Janeiro, v. 36, Supl. 1, p. 1-13, 2020. Disponível em: $<$ https://doi.org/10.1590/01002-311X00188718>. Acesso em: 03 abr. 2020.

CARVALHO, T. K. N. et al. Plantas usadas por uma comunidade rural na depressão sertaneja no Nordeste do Brasil. Revista de Biologia e Farmácia, Campina Grande, v. especial, p. 92-120, 2012.

CASTRO, K. N. C. et al. Ethnobotanical and ethnoveterinary study of medicinal plants used in the municipality of Bom Princípio do Piauí, Piauí, Brazil. Journal of Medicinal Plants Research, v. 10, n. 23, p. 318-330, 2016. Disponível em: $<$ https://ainfo.cnptia.embrapa.br/digital/bitstream/item/155545/1/ArtigoKarinaNeoobJouMe dicPlantsResearchJune2016.pdf>. Acesso em: 01 fev. 2020.

CECATTI, J. G. et al. Aborto no Brasil: um enfoque demográfico. Revista Brasileira de Ginecologia e Obstetrícia, São Paulo, v. 32, n. 3, p. 105-111, 2010. Disponível em: $<$ https://www.scielo.br/pdf/rbgo/v32n3/a02v32n3.pdf $>$. Acesso em: 01 fev. 2020.

CHAVES, E. M. F.; BARROS, R. F. M. Diversidade e uso de recursos medicinais do carrasco na APA da Serra da Ibiapaba, Piaú, Nordeste do Brasil. Revista Brasileira de Plantas Medicinais, Botucatu, v.14, n.3, p.476-486, 2012. Disponível em: $<$ https://www.scielo.br/scielo.php?pid=S1516-

05722012000300009\&script=sci_arttext\&tlng=pt>. Acesso em: 11 fev. 2020. 
NUNES, A. M. M.; SILVA, V. A. O uso de plantas abortivas no Nordeste Brasileiro: uma revisão. Ethnoscientia v.6 n. 2 , especial, 2021. DOI: 10.22276/ethnoscientia.v6i2.370

CORDEIRO, J. M. P.; FÉLIX, L. P. Conhecimento botânico medicinal sobre espécies vegetais nativas da caatinga e plantas espontâneas no agreste da Paraíba, Brasil. Revista Brasileira de Plantas Medicinais, Botucatu, v. 16, n. 3, p. 685-692, 2014. Disponível em: $<$ https://doi.org/10.1590/1983-084x/13_077>. Acesso em: 11 fev. 2020.

DINIZ, D. et al. Aborto: 20 anos de pesquisas no Brasil. Cadernos de Saúde Pública, Rio de Janeiro, v. 25, n. 4, p. 939-942, 2009. Disponível em: $<$ https://www.scielo.br/pdf/csp/v25n4/25.pdf $>$. Acesso em: 07 jan. 2020.

FEIJO, E.V.R.S. et al. Levantamento preliminar sobre plantas medicinais utilizadas no bairro Salobrinho no município de Ilhéus, Bahia. Revista Brasileira de Plantas Medicinais, Botucatu, v.15, n.4, p. 595-604, 2013. Disponível em: $<$ https://www.scielo.br/pdf/rbpm/v15n4/a17v15n4.pdf>. Acesso em: 10 jan. 2020.

GORRIL, L. E. et al. Risco das plantas medicinais na gestação: uma revisão dos dados de acesso livre em língua portuguesa. Arq. Ciênc. Saúde UNIPAR, Umuarama, v. 20, n. 1, p. 67-72, jan. - abr. 2016. Disponível em:

$<$ https://revistas.unipar.br/index.php/saude/article/view/5515>. Acesso em: 20 mar. 2020.

GOMES, E. C. S. et al. Plantas da Caatinga de uso terapêutico: levantamento etnobotânico. Engenharia Ambiental, Espírito Santo, v. 5, n. 2, p. 74 - 85, 2008. Disponível em: $<$ http://ferramentas.unipinhal.edu.br/engenhariaambiental/viewarticle.php?id=130\&layout= abstract>. Acesso em: 11 fev. 2020.

GOMES, T. B.; BANDEIRA, F. P. S. Uso e diversidade de plantas medicinais em uma comunidade quilombola no Raso da Catarina, Bahia. Acta Botanica Brasilica, Feira de Santana, v. 26, n. 4, p. 796-809, 2012. Disponível em:

$<$ https://core.ac.uk/download/pdf/205741177.pdf>. Acesso em: 10 jan. 2020.

GUERRA, N. M. et al. Usos locais de espécies vegetais nativas em uma comunidade rural no semiárido nordestino (São Mamede, Paraíba, Brasil). Revista de Biologia e Farmácia, Campina Grande, v. especial, p. 184-210, 2012. Disponível em: $<$ http://www.academia.edu/download/33466859/USOS_LOCAIS_DE_ESPECIES_VEGET AIS_NATIVAS_EM_UMA_COMUNIDADE_RURAL_PUBLICADŌ.pdf $>$. Acesso em: 07 jan. 2020.

LEITE, A. P. et al. Uso e conhecimento de espécies vegetais úteis em uma comunidade rural no vale do Piancó (Paraíba, Nordeste, Brasil). Revista de Biologia e Farmácia, Campina Grande, v. especial, p. 133-157, 2012. Disponível em: $<$ https://www.academia.edu/download/33466867/USO_E_CONHECIMENTO_DE_ESPE CIES_VEGETAIS_UTEIS_Itaporanga_PUBLICADO.pde.p $>$. Acesso em: 10 jan. $2 \overline{0} 20$.

LIMA, I. E. O. et al. Comercialização de plantas medicinais no município de Arapiraca-AL. Revista Brasileira de Plantas Medicinais, Campinas, v. 18, n. 2, p. 462-472, 2016. Disponível em: $<$ https://www.scielo.br/scielo.php?pid=S151605722016000200462\&script=sci_arttext\&tlng=pt $>$. Acesso em: 20 mar. 2020.

LUCENA, J. E. X. et al. Efeito antinociceptivo e antiinflamatório do extrato aquoso da entrecasca de Coutarea hexandra Schum.(Rubiaceae). Revista Brasileira de Farmacognosia, João Pessoa, v. 16, n. 1, p. 67-72, 2006. Disponível em: 
NUNES, A. M. M.; SILVA, V. A. O uso de plantas abortivas no Nordeste Brasileiro: uma revisão. Ethnoscientia v.6 n. 2 , especial, 2021. DOI: 10.22276/ethnoscientia.v6i2.370

$<$ https://www.scielo.br/scielo.php?pid=S0102-695X2006000100012\&script=sci_arttext $>$. Acesso em: 07 jan. 2020.

LUCENA, J. E. X. et al. Uso de recursos vegetais da caatinga em uma comunidade rural no curimataú paraibano (nordeste do Brasil). Polibotánica, México, n. 34, p. 237-258, 2012. $<$ http://www.scielo.org.mx/pdf/polib/n34/n34a12.pdf>. Acesso em: 10 jan. 2020.

MACEDO, J. G. F. et al. Analysis of the variability of therapeutic indications of medicinal species in the Northeast of Brazil: comparative study. Evidence-Based Complementary and Alternative Medicine, v. 2018, p.28, 2018. Disponível em:

$<$ https://www.hindawi.com/journals/ecam/2018/6769193/abs/>. Acesso em: 29 mar. 2020.

MADALENO, I. M. Plantas da medicina popular de São Luís, Brasil. Boletim do Museu

Paraense Emílio Goeldi. Ciências Humanas, Belém, v. 6, n. 2, p. 273-286, 2011.

Disponível em: $<$ https://www.scielo.br/scielo.php?pid=S1981-

$81222011000200002 \&$ script=sci_arttext\&tlng=pt>. Acesso em: 19 dez. 2019.

MATOS, F. J. A. Farmacognosia de Luffa operculata Cogn. Rev Bras Farm, v. 60, n. 7/9, p. 69-76, 1979.

MELO, A. et al. Uso de plantas medicinais na gestação. RETEC-Revista de Tecnologias, Ourinhos, v. 9, n. 2, p. 101-109, 2017. Disponível em:

$<$ https://www.fatecourinhos.edu.br/retec/index.php/retec/article/view/234>. Acesso em: 27 jan. 2020.

MENEZES, G. et al. Aborto e saúde no Brasil: desafios para a pesquisa sobre o tema em um contexto de ilegalidade. Cadernos de Saúde Pública, Rio de Janeiro, v. 36, Supl. 1, p. 1-14,2020.Disponível em:

$<$ https://www.scielosp.org/article/csp/2020.v36suppl1/e00197918/pt/>. Acesso em: 03 mai. 2020 .

MENGUE, S. S. et al. Uso de plantas medicinais na gravidez. Revista Brasileira de Farmacognosia, Curitiba, v. 11, n. 1, p. 21-35, 2001. Disponível em: $<$ https://www.scielo.br/pdf/rbfar/v11n1/a04v11n1.pdf $>$. Acesso em: 10 jan. 2020.

MOREIRA, L. M. A. et al. Associação entre o uso de abortifacientes e defeitos congênitos. RBGO, São Paulo, v. 23, n. 8, p. 517-521, 2001. Disponível em: $<$ https://www.scielo.br/pdf/rbgo/v23n8/11294>. Acesso em: 20 dez. 2019.

NETO, F. R. G. et al. Estudo etnobotânico de plantas medicinais utilizadas pela Comunidade do Sisal no município de Catu, Bahia, Brasil. Revista Brasileira de Plantas Medicinais, Campinas, v. 16, n. 4, p. 856-865, 2014. Disponível em: $<$ https://www.scielo.br/pdf/rbpm/v16n4/a11v16n4.pdf>. Acesso em: 14 mar. 2020.

NUNES, M. D. et al. The mutagenic, DNA-damaging and antioxidative properties of bark and leaf extracts from Coutarea hexandra (Jacq.) K. Schum. Environmental Toxicology and Pharmacology, v. 33, n. 2, p. 297-303. 2012. Disponível em: $<$ https:/www.sciencedirect.com/science/article/pii/S1382668911001803?via\%3Dihub>. Acesso em: 11 fev. 2020. 
NUNES, A. M. M.; SILVA, V. A. O uso de plantas abortivas no Nordeste Brasileiro: uma revisão. Ethnoscientia v.6 n. 2 , especial, 2021. DOI: 10.22276/ethnoscientia.v6i2.370

NUNES, M. D. et al. Histórias de aborto provocado entre adolescentes em Teresina, Piauí, Brasil. Ciência \& Saúde Coletiva, Rio de janeiro, v. 18, p. 2311-2318, 2013. Disponível em: <https://www.scielosp.org/article/csc/2013.v18n8/2311-2318/pt/>. Acesso em: 14 mar. 2020 .

OLIVEIRA, D. R. et al. Ethnopharmacological study of Stryphnodendron rotundifolium in two communities in the semi-arid region of northeastern Brazil. Rev. Bras. Farmacogn, v. 24, n. 2, p. 124-132, 2014. Disponível em: <https://www.scielo.br/pdf/rbfar/v24n2/0102695X-rbfar-24-02-00124.pdf>. Acesso em: 11 fev. 2020.

OMS. Who traditional medicine strategy: 2014-2020, Geneva, 2013. Disponível em: $<$ https://nacoesunidas.org/oms-proibicao-nao-reduz-numero-de-abortos-e-aumentaprocedimentos-inseguros/>. Acesso em: 11 fev. 2020.

PEDROSA, K. M. et al. Uso e disponibilidade local de Sideroxylon obtusifolium (roem. \& schult.) t.d. penn. (quixabeira) em três regiões da depressão sertaneja da paraíba, nordeste do brasil. Biofar Revista de Biologia e Farmácia, v. especial, p. 158-183, 2012.

PIRES, A. M.; ARAÚJO, P. S. Percepção de risco e conceitos sobre plantas medicinais, fitoterápicos e medicamentos alopáticos entre gestantes. Revista baiana de saúde pública. Salvador, v. 35, n. 2, p. 320-333, 2011. Disponível em:

<https://www.academia.edu/download/32609263/a2445.pdf>. Acesso em: 11 fev. 2020.

PONTES, S. M. et al. Utilização de plantas medicinais potencialmente nocivas durante a gestação na cidade de Cuité-PB. Comunicação em Ciências da Saúde, Campina Grande, v. 23, n. 4, p. 305-311, 2012. Disponível em:

$<$ http://bvsms.saude.gov.br/bvs/artigos/utilizacao_plantas_medicinais_potencialmente.pdf $>$. Acesso em: 24 abr. 2020.

ROQUE, A. A.; LOIOLA, M. I. B. Potencial de uso dos recursos vegetais em uma comunidade rural no Semiárido Potiguar. Revista Caatinga, Mossoró, v. 26, n. 4, p. 88 98, 2013. disponível em: <https://www.redalyc.org/pdf/2371/237129900011.pdf > Acesso em: 07 jan. 2020.

ROQUE, A. A. et al. Uso e diversidade de plantas medicinais da Caatinga na comunidade rural de Laginhas, município de Caicó, Rio Grande do Norte (nordeste do Brasil). Revista Brasileira de Plantas Medicinais, Botucatu, v. 12, n. 1, p. 31-42, 2010. Disponível em: $<$ https://www.scielo.br/scielo.php?pid=S1516-05722010000100006\&script=sci_arttext $>$. Acesso em: 21 fev. 2020.

RUIZ, A. L. T. G. et al. Farmacologia e Toxicologia de Peumus boldus e Baccharis genistelloides. Revista Brasileira de Farmacognosia Brazilian Journal of Pharmacognosy, João Pessoa, v. 18, n. 2, p.295-300, 2008. https://www.scielo.br/pdf/rbfar/v18n2/25.pdf. Acesso em: 11 fev. 2020

SILVA, T. S.; FREIRE, E. M. X. Abordagem Etnobotânica sobre plantas medicinais citadas por populações do entorno de uma unidade de conservação da caatinga do Rio Grande do Norte, Brasil. Revista Brasileira de Plantas Medicinais, Botucatu, v. 12, n. 4, p. 427-435, 2010. Disponível em: $<$ https://www.scielo.br/scielo.php?pid=S1516-

05722010000400005\&script=sci_arttext\&tlng=pt $>$. Acesso em: 04 jan. 2020. 
NUNES, A. M. M.; SILVA, V. A. O uso de plantas abortivas no Nordeste Brasileiro: uma revisão. Ethnoscientia v.6 n. 2 , especial, 2021. DOI: $10.22276 /$ ethnoscientia.v6i2.370

SILVA, J. N. et al. Plantas utilizadas como abortivas no município de Bom Jardim-PE. Revista de Biologia e Farmácia, Campina Grande, v. 04, n. 01, 2010. Disponível em: $<$ http://plone.ufpb.br/nephf/contents/documentos/artigos/fitoterapia/plantas-utilizadascomo-abortivas-no-municipio-de-bom-jardim-2013-pe.pdf>. Acesso em: 06 mar. 2020.

SILVA, N. C. B. et al. Uso de plantas medicinais na comunidade quilombola da Barra II Bahia, Brasil. Boletín Latinoamericano y del Caribe de Plantas Medicinales y

Aromáticas, Chili, v. 11, n. 5, 435-453. 2012. Disponível em:

$<$ https://www.redalyc.org/pdf/856/85624131006.pdf >. Acesso em: 10 abr. 2020.

SILVA, F. J. et al. Plantas medicinais e suas indicações ginecológicas: estudo de caso com moradoras de Quixadá, CE, Brasil. Revista Brasileira de Biociências, Porto Alegre, v. 14, n.3, p. 193-201, 2016. Disponível em:

$<$ http://www.ufrgs.br/seerbio/ojs/index.php/rbb/article/view/3697>. Acesso em: 02 fev. 2020 .

SILVA, I. A. N. et al. Cannabis sativa and pregnancy: a review. Revista Biotemas, Florianópolis, v.32, n. 2, p. 1-11, 2019. Disponível em:

$<$ https://dialnet.unirioja.es/servlet/articulo?codigo=7014209>. Acesso em: 04 fev. 2020.

SOARES, Z. A. et al. Local botanical knowledge about useful species in a semi-arid region from Northeastern Brazil. Gaia Scientia, João Pessoa, v. 7, n. 1, p. 80-103, 2013. Disponível em: <http://www.academia.edu/download/33466440/18022-32691-1-SM.pdf>. Acesso em: 10 abr. 2020.

VASCONCELOS, G. P. S.; CUNHA, E. V. L. Levantamento de Plantas Medicinais Utilizadas por Indígenas Potiguaras da Aldeia São Francisco (Litoral Norte da Paraíba). Gaia Scientia, João Pessoa, v. 7, n. 1, p. 146-156, 2013. Disponível em: $<$ https://periodicos.ufpb.br/index.php/gaia/article/view/24272\#: :text=O\%20objetivo\%20da $\% 20$ pesquisa $\% 20$ foi,Registraram\%2Dse $\% 2072 \% 20$ plantas $\% 20$ medicinais $>$. Acesso em: 20 abr. 2020. 